\title{
Impact on the Onset of Psychosis of a Polygenic Schizophrenia-Related Risk Score and Changes in White Matter Volume
}

\author{
Fabienne Harrisberger ${ }^{a, b}$ Renata Smieskova ${ }^{a, b}$ Tobias Eglic Andor E. Simon ${ }^{d, e}$ \\ Anita Riecher-Rösslera, Paolo Fusar-Polih,i Andreas Papassotiropoulos ${ }^{\mathrm{b}, \mathrm{c}, \mathrm{f}, \mathrm{g}}$ \\ Stefan Borgwardta,b,h
}

\begin{abstract}
${ }^{a}$ Neuropsychiatry and Brain Imaging, Department of Psychiatry (UPK), University of Basel, ${ }^{\text {bPsychiatric }}$ University Clinics, University of Basel, Basel, 'Division of Molecular Neuroscience, Department of Psychology, University of Basel, Basel, dUniversity Hospital of Psychiatry, University of Bern, Bern, eSpecialized Early Psychosis Outpatient Service for Adolescents and Young Adults, Department

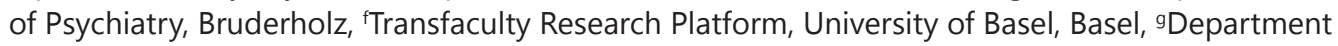
Biozentrum, Life Sciences Training Facility, University of Basel, Basel, Switzerland; ' $E$ Early Psychosis: Interventions and Clinical Detection (EPIC) lab, Department of Psychosis Studies, Institute of Psychiatry, Psychology \& Neuroscience, King's College London, London, United Kingdom; 'Department of Brain and Behavioral Sciences, University of Pavia, Pavia, Italy
\end{abstract}

\section{Key Words}

Psychosis - MRI • Polygenic schizophrenia-related risk - PSRS • Genetic risk • White matter • First episode psychosis • At-risk mental state $•$ Clinical high risk $•$ Schizophrenia $•$ Transition • Imaging • Bipolar

\begin{abstract}
Background: Reductions in the volume of brain white matter are a common feature in schizophrenia and bipolar disorder while the association between white matter and polygenic schizophrenia-related risk is unclear. To look at the intermediate state between health and the full-blown disorder, we investigated this aspect in groups of patients before and after the onset of psychosis. Methods: On a 3 Tesla scanner, total and regional white matter volumes were investigated by structural magnetic resonance imaging (MRI) in the following groups: 37 at-risk mental state patients (ARMS), including 30 with no transition to psychosis (ARMS-NT) and 7 with a transition to psychosis (ARMS-T) pooled with 25 first episode psychosis (FEP) patients. These $T_{1}$-weighted images were automatically processed with the FreeSurfer software and compared with an odds-ratio-weighted polygenic schizophrenia-related risk score (PSRS) based on the publicly available top white matter single-nucleotide polymorphisms. Results: We found no association, only a trend, between PSRS and white matter volume over all groups $(\beta=0.24, p=0.07,95 \%$ confidence interval $=[-0.02-0.49])$. However, a higher PSRS was significantly associated with a higher probability of being assigned to the ARMS-T + FEP group rather than to the ARMS-NT group $(\beta=0.70, p=0.02,95 \%$ confidence interval $=$ $[0.14-1.33])$; there was no such association with white matter volume. Additionally, a positive
\end{abstract}


Harrisberger et al.: White Matter and Genetic Risk in Psychosis

association was found between PSRS and the Brief Psychiatric Rating Scale (BPRS) total score for the pooled ARMS-NT/ARMS-T+FEP sample and for the ARMS-T + FEP group also, but none for the ARMS-NT group only. Conclusion: These findings suggest that at-risk mental state patients with a transition and first-episode psychosis patients have a higher genetic risk for schizophrenia than at-risk mental state patients with no transition to psychosis; this risk was associated with psychopathological symptoms. Further analyses may allow polygenic schizophrenia-related risk scores to be used as biomarkers to predict psychosis.

(C) 2018 The Author(s)

Published by S. Karger AG, Basel

\section{Introduction}

Schizophrenia and bipolar disorder can be severe mental disorders with high heritability $[1,2]$, high genetic relationship [3] and an overlap in symptomatology. However, the profile of common genetic variants that contribute to the susceptibility to schizophrenia and/or bipolar disorder are still under investigation. The Psychiatric Genomics Consortium (PGC) performed the largest study to date and identified 108 loci associated with schizophrenia [4]. Furthermore, it has been estimated that thousands of genetic variants with small effects are involved in the susceptibility to schizophrenia and bipolar disorder and might account for around $23 \%$ of the variation in liability to schizophrenia [5-7]. If the risk allele count of Single Nucleotide Polymorphisms (SNP) are combined into a single polygenic schizophreniarelated risk score, this might be associated with disease-characteristic endophenotypes that are more closely related to the biological processes than are diagnostic criteria [8-10].

Another robust marker that is associated with schizophrenia and bipolar disorder is alteration in brain structure [11-13]. Moreover, in schizophrenia patients, reductions in white matter are largely driven (94\%) by genetic factors [14]. Several studies have therefore investigated an association between white matter volume and a schizophrenia SNP score. Firstly, a publication by Terwisscha van Scheltinga identified 186 schizophrenia-associated SNPs associated with white matter volume in both schizophrenia patients $(n=152)$ and healthy controls $(n=142)$ [15]. Secondly, a study in healthy individuals $(n=122)$ found no association between white matter volume and the same set of SNPs [16]. Thirdly, a study with schizophrenia and bipolar patients, first-degree relatives of schizophrenia patients $(n=94)$ and healthy controls $(n=89)$ found an association between 7 SNPs (not included in the above risk score) and white matter volume [17]. Fourthly, a study ( $\mathrm{n}=1470)$ and its replication $(n=2725)$ in healthy individuals again detected no association - in two and three independent cohorts, respectively - between white matter volume and SNPs from the PGC consortium $[18,19]$.

To further investigate the potentially important association between white matter volume and the polygenic schizophrenia-related risk score (PSRS) in schizophrenia and bipolar disorder patients but not healthy controls, we investigated this aspect in groups of patients before and after the onset of psychosis. More specifically, the analysis included first-episode psychosis patients (FEP) experiencing their first episode of psychosis and at high clinical risk of psychosis [20] and at-risk mental state (ARMS) patients, who showed signs and symptoms that might precede a first psychotic episode [21]. We hypothesize that we would find and replicate the association between the 186 schizophrenia-associated risk score and total white matter volume in a cohort of ARMS and FEP patients. Furthermore, we also investigated the association between this PSRS and specific white matter regions.

\section{Materials and Methods}

Participants and clinical assessment

ARMS and FEP patients included in this study were recruited, assessed and treated in the early detection of psychosis research program (Früherkennung von Psychosen; FePsy) at the University of Basel, Psychiatric University Clinics Basel, Switzerland[22, 23]. All 
individuals were assessed by the Basel Screening Instrument for Psychosis (BSIP) [24], the Brief Psychiatric Rating Scale (BPRS), the Scale for the Assessment of Negative Symptoms (SANS) and the Global Assessment of Functioning (GAF), at the time of the MRI scan. We additionally obtained information on current and previous psychotropic medication, nicotine, and illegal drug consumption, using a semi-structured interview adapted from the Early Psychosis Prevention and Intervention Centre Drug and Alcohol Assessment Schedule (eppic.org.au).

ARMS was defined in accordance with the criteria of Yung and resulted in the inclusion of $\mathrm{N}=37$ ARMS individuals in the study, [24] The FEP patients $(\mathrm{N}=25)$ met the operational criteria of Yung et al. [25] and fulfilled criteria for acute psychotic disorder according to $I C D-10$ or $D S M-V$ but not for schizophrenia. For a more detailed description of the study procedure see Harrisberger et al. [26] All individuals were antipsychotic-naïve at the time of scanning, whereas 17 of the ARMS individuals were receiving antidepressants. 7 ARMS patients underwent the transition to psychosis within four years of MR scanning. 13 of our FEP patients were antipsychotic-naïve, 3 were antipsychotic-free and 9 were receiving antipsychotic medication at the time of scanning (two quetiapine, two risperidone, two olanzapine, one clozapine, one aripiprazole, one paliperidone). In the antipsychotic-free group, antipsychotic medication (two aripiprazole, one risperidone) had been stopped 4, 19 and 24 months previously, respectively. Antipsychotic dose was converted into chlorpromazine (CPZ) equivalents using the Suppl. Table 'Antipsychotic dose conversion' in Ho et al. [27] The mean chlorpromazine equivalents (standard deviation) were $250.70 \mathrm{mg}$ (200.76). Of all FEP patients, 3 received only antidepressants alone and 4 were on combined treatment with antidepressants and antipsychotics. In this analysis, the patients were grouped into ARMS with no transition to psychosis (ARMS-NT) and ARMS with a transition to psychosis (ARMS-T) pooled with FEP patients.

Exclusion criteria were history of previous psychotic disorder, psychotic symptomatology secondary to an 'organic' disorder, psychotic symptoms associated with an affective psychosis or a borderline personality disorder, substance abuse according to International Statistical Classification of Diseases, 10th Revision (ICD-10) research criteria, head trauma, neurological illness, serious medical or surgical illness, age under 18 years, inadequate knowledge of the German language, and IQ less than 70 as measured by the Mehrfachwahl Wortschatz [Multiple Choice Vocabulary] Test Form B (MWT-B).

All participants provided written informed consent and received compensation for participating. The study has permission from the ethics committee of North-West and Central Switzerland (EKNZ).

\section{MRI acquisition}

All scans were performed at Basel University Hospital on a 3T magnetic resonance imaging (MRI) scanner (Siemens Magnetom Verio, Siemens Healthcare, Erlangen, Germany), using a 12-channel phased-array radio frequency head coil. For structural images, a 3D $\mathrm{T}_{1}$ weighted magnetization prepared rapid gradient echo (MPRAGE) sequence was used with the following parameters: an inversion time of $1,000 \mathrm{~ms}$, flip angle $=8$ degrees, TR $=2 \mathrm{~s}$, TE $=3.37 \mathrm{~ms}, \mathrm{FOV}=25.6 \mathrm{~cm}$, acquisition matrix $=256 \times 256 \times 176$, resulting in 176 contiguous sagittal slices with $1 \times 1 \times 1 \mathrm{~mm}^{3}$ isotropic spatial resolution. All scans were screened for gross radiological abnormalities by resident neuroradiologists.

\section{Genotyping and Imputation}

DNA was extracted from whole blood samples using the QIAamp ${ }^{\circledR}$ DNA Blood Maxi kit, according to standard procedures (Qiagen Inc., Chatsworth, CA). DNA samples were further processed on the Affymetrix ${ }^{\circledR}$ Genome-Wide Human SNP Array 6.0, as described in the Genome-Wide Human SNP Nsp/Sty 6.0. User Guide (Affymetrix, Santa Clara, CA, USA) in one centralized microarray facility. Generation of SNP calls and array quality control were performed using the Affymetrix Genotyping Console Software 3.0 (Affymetrix Inc.). According to the manufacturer's recommendation, contrast quality control (QC) was chosen as QC metric, using the default value of 0.4 . All samples passing QC criteria were subsequently 
genotyped using the Birdseed (v2) algorithm, leading to a total of 921,523 genotyped SNPs per sample. Appropriate SNP QC filtering was applied in PLINK 1.9 software, where the gender check in PLINK led to the exclusion of 3 individuals (Purcell S, Chang CC General Usage - PLINK 1.9.2015. https://www.cog-genomics.org/plink2/general usage) [28]. They were excluded prior to the analyses and are not included in the sample sizes shown.

Population stratification was assessed using principal component analysis implemented in the EIGENSTRAT software [29] to detect genotypic outliers - with default parameters: $>6$ standard deviations on any of the top ten principal components (PC) in five iterations - and corrected for potential population substructure by analyzing all array-based pruned, autosomal SNPs. Eight individuals were identified as outliers and therefore excluded from further analyses. They are not included in the sample sizes shown.

Prior to autosome-wide genotype imputation, haplotype estimation was performed using SHAPEITv2 [30], allowing a maximum of 5\% per individual and per SNP missing rate for observed markers. After pre-phasing, genotype imputation was performed using IMPUTE [30] v2.3.0, which imputes missing genotypes using a multi-population reference panel [31, 32]. The integrated variant callset of 1,092 individuals from the 1000 Genomes Project (release v3 in NCBI build 37/hg19 coordinates, March 2012) served as panel data (http://mathgen.stats.ox.ac.uk/impute/ALL_1000G_phase1integrated_v3_impute_macGT1. tgz). Only genotype calls exceeding a probability score of $90 \%$ were converted into genotype calls for statistical analysis using plink [33].

\section{PSRS calculation}

PSRS were calculated, following the suggestions of Wray et al. [34], by taking LD pruned loci associated with white matter volume identified by Terwischa van Scheltinga et al., 2013 [15]. All 186 SNPs could be used to calculate the PSRS. 57 SNPs represented on the Affymetrix 6.0 Genotyping Array and 129 imputed SNPs were included (See Suppl. Table 2 [15]). In summary, the number of risk alleles per person was weighted for each SNP by the logarithm of its odds ratio as reported in the PGC SZ dataset [4] and summed across SNPs [7] using the PLINK 1.9 software (Purcell S, Chang CC General Usage - PLINK 1.9.2015. https:// www.cog-genomics.org/plink2/general usage and [28]). The PSRS was then corrected for the first twenty genotypic PCs and the number of SNPs used to calculate the PSRS by using the z-transformed residuals of a linear regression.

\section{Image processing}

Total white matter volume was segmented from $\mathrm{T}_{1}$-weighted MPRAGE images with the freely available and validated segmentation software FreeSurfer software version 6.0.0 (http://surfer.nmr.mgh. harvard.edu) [35] and quality checked according to standardized ENIGMA protocols (http://enigma.ini.usc.edu/). Raw volumes for the total white matter volume were extracted as well as segmented volumes of 68 white matter volumes (34 left and 34 right) in white matter regions. From these white matter regions, the following 6 bilateral white matter regions were selected from a systematic review [36]: caudal and rostral anterior cingulate, entorhinal, parahippocampal, superior frontal and frontal pole white matter, left and right each. All were separately corrected for intracranial volume (ICV), age, gender and CPZ equivalents of antipsychotics, by using the z-transformed residuals of a linear regression. An outlier control resulted (mean $\pm 3.5 \mathrm{SD}$ ) in the exclusion of 1 individual.

Statistical Analysis

The R 3.3.2 software (R Core Team, 2013 "R: A language and Environment for Statistical Computing" http://www.R-project.org) with the packages stats was used for statistical, group-related analysis. Chi-square tests or t tests were used to test the distribution between diagnosis group and gender, handedness, CPZ equivalents, antipsychotics, antidepressants, alcohol consumption, cannabis consumption, or age, years of education, IQ BPRS, BPRS positive symptoms cluster, BPRS negative symptoms cluster, SANS, GAF, smoking respectively. Values are presented as mean \pm SD (see table 1 ). We combined several items of the BPRS into the following symptom clusters:

\section{KARGER}


- positive (suspiciousness (BPRS9), hallucinations (BPRS10) and unusual thought content (BPRS11)),

- negative (blunted affect (BPRS16), emotional withdrawal (BPRS17), motor retardation (BPRS18)), activation (elevated mood (BPRS7), excitement (BPRS21) and motor hyperactivity (BPRS23)) and

- affect (depression (BPRS3), suicidality (BPRS4) and guilt (BPRS5)) [37].

In addition, associations between clinical symptoms and PSRS or white matter volume were examined by linear regression analysis and corrected for multiple comparison. The relationship between corrected PSRS (corrected for the first twenty genotypic PCs and the number of SNPs used to calculate the PSRS) and the corrected white matter volume (corrected for ICV, age, gender and CPZ equivalents of antipsychotic dose) was assessed in a linear regression model. We then fitted a logistic regression using the generalized linear model function in $\mathrm{R}$ with diagnosis status as binary dependent variable and the corrected white matter volume and the corrected PSRS score as independent variables (both having similar variance between groups).

\section{Results}

\section{Clinical and sociodemographic characteristics}

There were no significant differences between the investigated groups with respect to gender $(p=0.68)$, handedness $(p=0.36)$, years of education $(p=0.84)$, MWT-B $(p=0.42)$, the number of individuals treated with antidepressants $(p=0.32)$, smoking $(p=0.45)$ or cannabis consumption $(\mathrm{p}=0.72)$. There were significant between-group differences in age $(\mathrm{p}=0.01)$, BPRS $(\mathrm{p}=0.001)$, BPRS positive symptoms cluster $(\mathrm{p}=0.001)$, BPRS negative symptoms cluster $(p=0.0004)$, SANS $(p=0.02)$, GAF ( $p=0.001)$, CPZ equivalents $(p=0.02)$, the number of patients treated with antipsychotics $(\mathrm{p}=0.01)$ and alcohol consumption $(\mathrm{p}=$ 0.01) (Table 1).

\section{Association between PSRS, white matter volume and diagnosis}

Linear regression analysis revealed no significant association, only a trend, between the PSRS and white matter volume $(\beta=0.24, \mathrm{p}=0.07,95 \% \mathrm{CI}=[-0.02-0.49]$, Table 2$)$ in

Table 1. Demographics and clinical characteristics. Abbreviations: AD: Antidepressants; AP: Antipsychotics; ARMS-NT: At-risk Mental State Individuals no transition; ARMS-T: At-risk Mental State Individuals with transition; BPRS: Brief Psychiatric Rating Scale; Cig: Cigarettes; CPZ, chlorpromazine; F: Female; FEP: FirstEpisode Psychosis Patients; GAF: Global Assessment of Functioning; l: left; M: Male; MWT-B: Mehrfachwahl Wortschatz Test [Multiple Choice Vocabulary] Form B; PSRS: Polygenic Schizophrenia-related Risk Score; r: right; SANS: Scale for the Assessment of Negative Symptoms; SD: Standard Deviation

\begin{tabular}{|c|c|c|c|c|}
\hline Characteristics & ARMS-NT $(n=30)$ & ARMS-T+FEP $(n=32)$ & Statistics & \\
\hline Gender M/F (\%M) & $23 / 7(77 \%)$ & $22 / 10(69 \%)$ & $\chi^{2}=0.17$ & $\mathrm{p}=0.68$ \\
\hline Mean age in years (SD) & $23.73(3.38)$ & $28.15(7.75)$ & $\mathrm{t}=-2.94$ & $\mathrm{p}=0.01$ \\
\hline Handedness $\mathrm{r} / \mathrm{l}(\% \mathrm{l})$ & $27 / 3(90 \%)$ & $25 / 7(78 \%)$ & $\chi 2=0.86$ & $\mathrm{p}=0.36$ \\
\hline Years of education (SD) & $13.68(2.21)$ & $13.83(3.31)$ & $\mathrm{t}=-0.20$ & $\mathrm{p}=0.84$ \\
\hline MWT-B (SD) & $112.42(14.15)$ & $108.96(16.29)$ & $\mathrm{t}=0.81$ & $\mathrm{p}=0.42$ \\
\hline BPRS (SD) & $36.57(7.68)$ & $47.79(15.14)$ & $\mathrm{t}=-3.57$ & $\mathrm{P}=0.001$ \\
\hline BPRS_pos (SD) & $5.67(2.19)$ & $9.48(4.96)$ & $\mathrm{t}=-3.80$ & $\mathrm{P}=0.001$ \\
\hline BPRS_neg (SD) & $4.57(2.22)$ & $6.97(2.65)$ & $t=-3.76$ & $\mathrm{p}=0.0004$ \\
\hline BPRS_act (SD) & $3.62(1.18)$ & $3.72(1.89)$ & $\mathrm{t}=-0.25$ & $\mathrm{p}=0.80$ \\
\hline BPRS_aff (SD) & $6.43(2.49)$ & $6.68(3.42)$ & $\mathrm{t}=-0.31$ & $\mathrm{p}=0.77$ \\
\hline SANS (SD) & $16.10(14.50)$ & $25.29(14.19)$ & $\mathrm{t}=-2.42$ & $\mathrm{p}=0.02$ \\
\hline GAF (SD) & $72.53(11.75)$ & $59.97(16.38)$ & $\mathrm{t}=3.49$ & $\mathrm{p}=0.001$ \\
\hline $\mathrm{CPZ}$ equivalents & $0(0)$ & $70.51(157.54)$ & $\mathrm{t}=-2.53$ & $\mathrm{p}=0.02$ \\
\hline AP no/yes (\%yes) & $30 / 0(0 \%)$ & $23 / 9(28 \%)$ & $\chi 2=7.73$ & $\mathrm{P}=0.01$ \\
\hline AD no/yes (\%yes) & $16 / 14(45 \%)$ & $22 / 10(32 \%)$ & $\chi 2=0.97$ & $\mathrm{p}=0.32$ \\
\hline Smoking cigarettes/day & $8.37(8.41)$ & $10.19(10.36)$ & $t=-0.76$ & $\mathrm{p}=0.45$ \\
\hline Alcohol: none/normal/extensive & $1 / 24 / 5$ & $11 / 15 / 6$ & $\chi^{2}=10.45$ & $\mathrm{p}=0.01$ \\
\hline Cannabis no/yes (\%y) & $20 / 10(33 \%)$ & $23 / 8(25 \%)$ & $\chi^{2}=0.13$ & $\mathrm{p}=0.72$ \\
\hline White matter volume (corrected) & $0.10(0.75)$ & $-0.08(1.24)$ & $\mathrm{t}=0.69$ & $\mathrm{p}=0.49$ \\
\hline PSRS scores (corrected) & $-0.29(0.93)$ & $0.27(1.08)$ & $\mathrm{t}=-2.19$ & $\mathrm{p}=0.03$ \\
\hline
\end{tabular}


our total sample. And separate analyses in the subgroups of ARMS-NT patients $(\beta=0.37$, $\mathrm{p}=0.11,95 \% \mathrm{CI}=[-0.09-0.82]$, Fig. 1 , Table 2$)$ or in the pooled ARMS-T+FEP patients $(\beta$ $=0.23, \mathrm{p}=0.15,95 \% \mathrm{CI}=[-0.09-0.54$, Fig. 1 , Table 2$)$ indicated no significant association. Further logistic regression analysis identified a significant main effect of the PSRS on the log odds of an individual being assigned to the ARMS-T+FEP state $(\beta=0.70, p=0.02,95 \% \mathrm{CI}=$ [0.14 - 1.33], Table 2, Fig. 2A). However, neither the main effect of white matter volume ( $\beta$ $=-0.33, \mathrm{p}=0.24,95 \% \mathrm{CI}=[-0.90-0.20]$, Table 2, Fig. $2 \mathrm{~B})$ nor the interaction effect of PSRS and white matter volume $(\beta=0.34, p=0.21,95 \% \mathrm{CI}=[-0.18-0.93]$, Table 2$)$ on the log odds was significant. Therefore, a higher PSRS score is associated with a higher likelihood that an individual would be assigned to the group of ARMS-T+FEP individuals than to the group of ARMS-NT individuals.

Furthermore, in 6 specified white matter regions (i.e. caudal and rostral anterior cingulate, entorhinal, parahippocampal, superior frontal and frontal pole white matter), there was no significant association with a PSRS.

Association between PSRS or white matter volume and clinical parameters

At the time of scanning, PSRS was positively associated with BPRS total score $(\mathrm{t}=3.16$, $\mathrm{p}=0.0026,95 \% \mathrm{CI}=[0.14-0.58])$ in the pooled ARMS-NT/ARMS-T+FEP sample. Separate

Table 2. Results of linear and logistic regression. Abbreviations: ARMS-NT: AtRisk Mental State no transition; ARMS-T: At-Risk Mental State with transition; ACME: Average causal mediation effect; ADE: Average direct effect; CI: Confidence Interval; FEP: First-Episode Psychosis; PSRS: Polygenic Schizophrenia-Related Risk Score

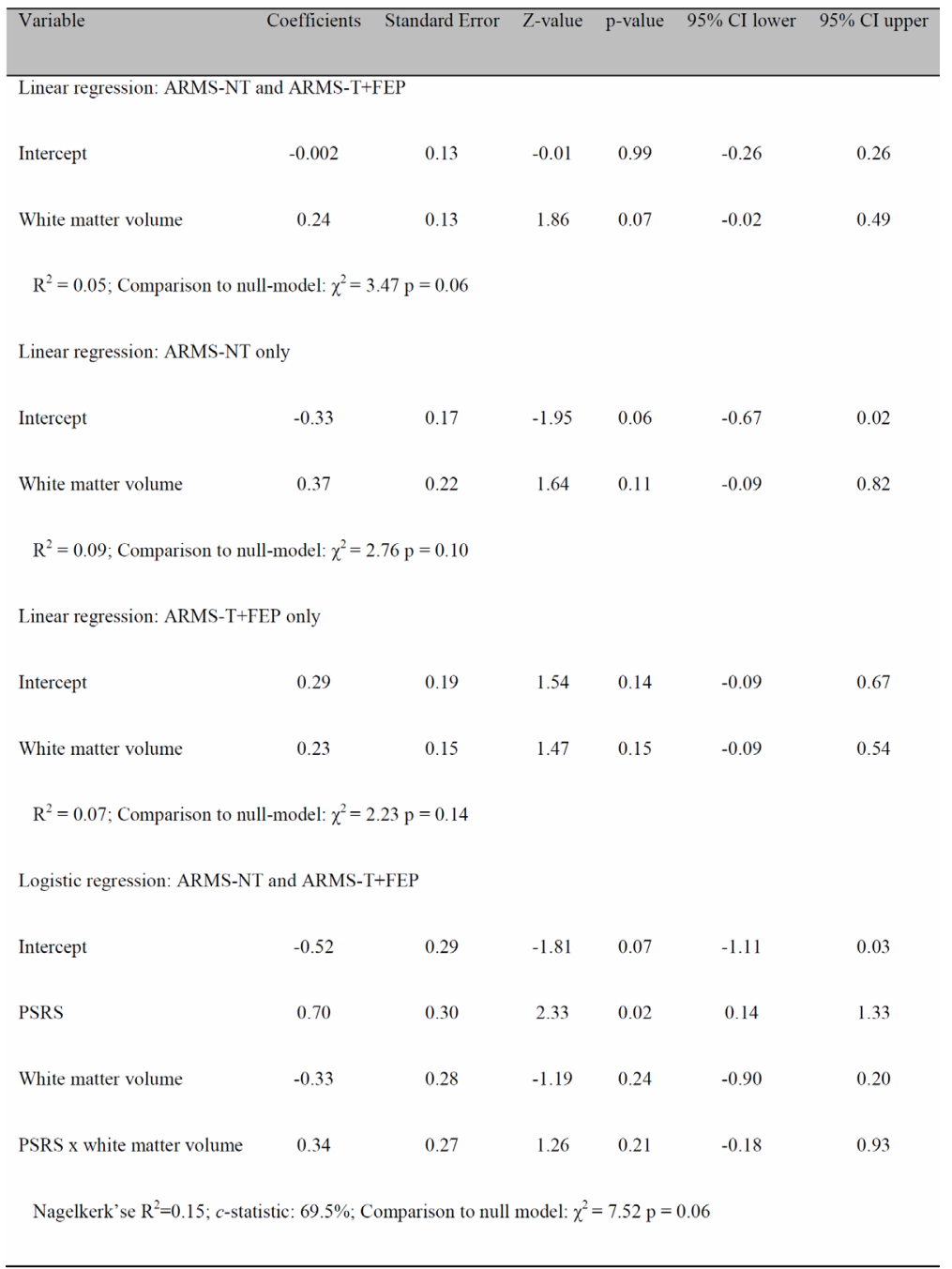


Fig. 1. Linear regression analysis of PSRS and white matter volume. Standardized residuals of the PSRS are adjusted for the first 20 genotypic PCs and the number of SNPs used to calculate the PSRS. Standardized residuals of the total white matter volume are adjusted on each side separately for ICV, age, gender and CPZ equivalents. Red dashed line, regression line with $95 \%$ confidence interval of ARMS-T+FEP cohort; blue dot-dashed line, regression line with $95 \%$ confidence interval of ARMS-NT cohort. ARMS-NT, at-risk mental state, no transition; ARMS_T, at-risk mental state, with transition; CPZ, chlorpromazine; FEP, first-episode psychosis; ICV, intracranial volume; PC, principal component; PSRS.

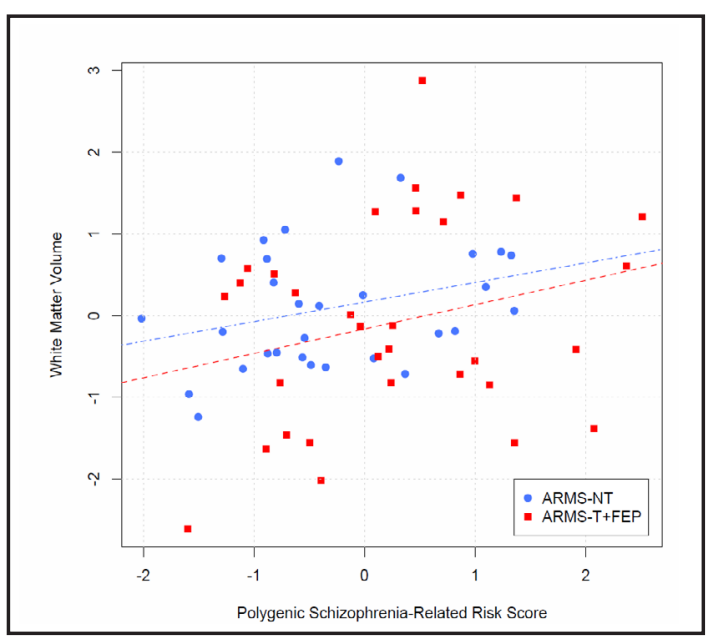

A

B
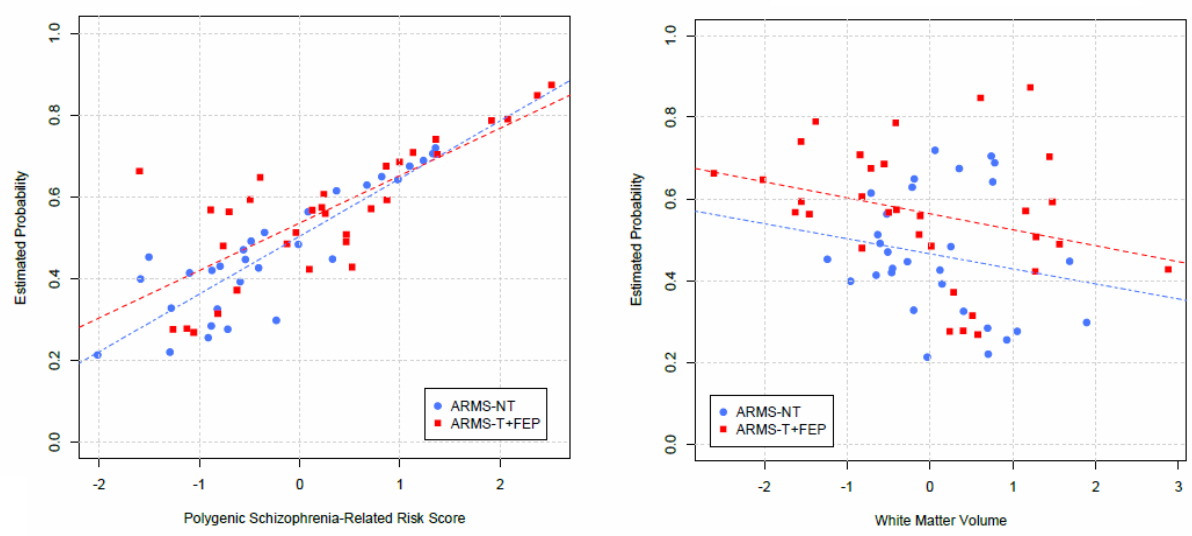

Fig. 2. Plot of estimated probability for being FEP or ARMS-T versus PSRS or WM respectively. Black dashed line, regression line with 95\% confidence interval of ARMS-T+FEP and ARMS-NT cohorts. A. The standardized residuals of the PSRS are adjusted for the first 20 genotypic PCs and the number of SNPs used to calculate the PSRS are plotted against the estimated probability of the logistic regression. B. Standardized residuals of the total white matter volume are adjusted on each side separately for ICV, age, gender and $\mathrm{CPZ}$ equivalents and plotted against the estimated probability of the logistic regression. ARMS-NT, at-risk mental state, no transition; ARMS-T, at-risk mental state, with transition; CPZ, chlorpromazine; FEP, firstepisode psychosis; PC, principal component; PSRS, Polygenic Schizophrenia-Related Risk Score; SNP, singlenucleotide polymorphism; WM, white matter volume.

analysis within the two groups revealed only an association for ARMS-T+FEP ( $\mathrm{t}=3.74$, $\mathrm{p}=0.001,95 \% \mathrm{CI}=[0.28-0.78])$, but none for ARMS-NT only $(\mathrm{t}=-1.52, \mathrm{p}=0.14,95 \% \mathrm{CI}=$ [-0.58 - 0.09]) (Fig. 3). Moreover, neither total white matter volume nor any of the 6 selected white matter regions were associated with clinical parameters. These results are corrected for multiple comparisons.

As there is a significant difference in age between the groups, age is plotted against the standardized residuals of the PSRS and against standardized residuals of the total white matter volume (Fig. 4). 
Fig. 3. Association between PSRS and BPRS total score. Black dashed line, regression line with $95 \%$ confidence interval of the combined ARMS-T+FEP and ARMS-NT cohorts. The standardized residuals of the PSRS are adjusted for the first 20 genotypic PCs and the number of SNPs used to calculate the PSRS are plotted against the BPRS total score. ARMSNT, at-risk mental state, no transition; ARMS-T, at-risk mental state, with transition; FEP, firstepisode psychosis; PC, principal component; PSRS, Polygenic Schizophrenia-Related Risk Score; SNP, single-nucleotide polymorphism; WM, white matter volume.

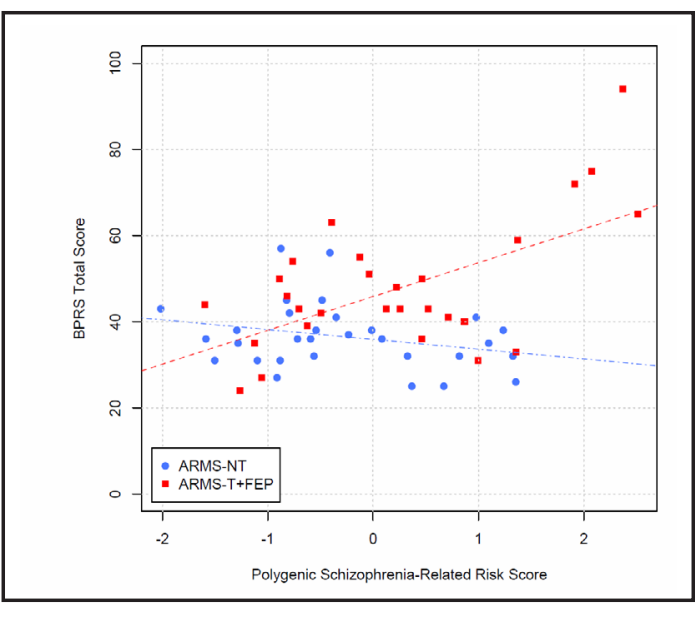

A

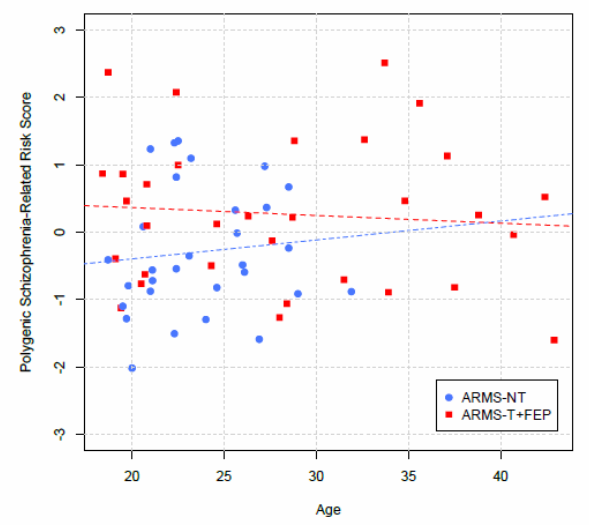

B

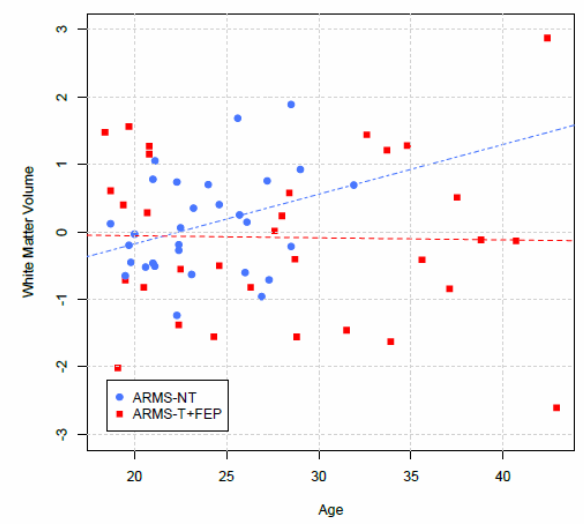

Fig. 4. Plot of age versus PSRS or WM respectively. Black dashed line, regression line with $95 \%$ confidence interval of ARMS-T+FEP and ARMS-NT cohorts. A. Age is plotted against the standardized residuals of the PSRS adjusted for the first 20 genotypic PCs and the number of SNPs used to calculate the PSRS. B. Age is plotted against standardized residuals of the total white matter volume adjusted on each side separately for ICV, age, gender and CPZ equivalents and plotted against the estimated probability of the logistic regression. ARMS-NT, at-risk mental state, no transition; ARMS-T, at-risk mental state, with transition; CPZ, chlorpromazine; FEP, first-episode psychosis; PC, principal component; PSRS, Polygenic SchizophreniaRelated Risk Score; SNP, single-nucleotide polymorphism; WM, white matter volume.

\section{Discussion}

To our knowledge, this is the first study to analyze an association between a polygenic schizophrenia-related risk score, white matter volume and the onset of psychosis. In ARMS and FEP patients, we could not confirm an association between white matter volumes and PSRS, only trend. However, a higher PSRS was significantly associated with a higher probability of being assigned to the ARMS-T+FEP group than to the ARMS-NT group. No such association was found with white matter volume. In addition, we found a positive association between PSRS and the BPRS total score.

In contrast to previous publications with schizophrenia and bipolar disorder patients $[14,16]$ we found no association between this PSRS and white matter volume. However, the results are in line with publications analyzing the association in healthy individuals only. 
[15-18]. This patient sample consisted of ARMS and FEP patients, but without schizophrenia and bipolar disorder patients or healthy controls. One possible explanation of these findings is that the association is not present in the early stages of the disease. This is also reflected by the fact that white matter volume alterations are known to be present in schizophrenia and bipolar disorder patients and also the first-episode state $[11,13,38-40]$ and less pronounced in ARMS [41]. Therefore, it might be speculated that white matter volume alterations occur only later in the development of the disorder, and are not detectable in this pooled patient cohort.

Although this genetic risk score was specifically selected to be associated with both white matter volume and schizophrenia [15], we could not detect this association in our sample. Nevertheless, we could show that this PSRS is associated with a higher probability of being in an ARMS with subsequent transition to psychosis or already being an FEP patient. The association with the early disease status, before the onset of schizophrenia or bipolar disorder, might be an indicator not only for a greater risk for schizophrenia but more importantly for the actual onset of psychosis, even in the ARMS. This might show that a higher schizophrenia-specific risk might be capable of separating ARMS-T from ARMS-NT in the early detection of psychosis. Bearing in mind that up to $22 \%$ (95\% 17\%-26\%) of ARMS patients undergo transition to psychosis within 3 years after the first presentation to clinical services [42] (see the meta-analytical eFig. 4), it might be speculated that with our transition rate of $23 \%$ four more patients in our sample with a high PSRS might exhibit a transition to psychosis. Our result indicated that ARMS-T and FEP share more schizophrenia-associated alleles than ARMS-NT and thus this might be a similarity marker for actual transition to psychosis in the ARMS patients. Understanding the genetic markers of impending vulnerability for psychosis in ARMS samples is of paramount relevance, given the poor research in this area. Indeed a recent meta-analysis of risk factors for psychosis within ARMS samples found no established genetic factors [43].

Additionally, a higher PSRS was associated with higher BPRS total score in the whole sample of patients and also in ARMS-T+FEP only, but not in ARMS-NT only. This positive association between a PSRS and the widely-used scale for assessing psychotic symptoms might provide genetic evidence for actual similarity of ARMS-T with FEP. Moreover, this result might also indicate that ARMS-T plus FEP together are genetically similar to schizophrenia and bipolar disorder patients. Vice versa, the absence of an association in the ARMS-NT group might indicate once again that the genetic basis is not shared with PSRS. This is consistent with the concept of a psychosis continuum, as the genetic liability is also found in another quantitative trait which composes disorder, namely the psychotic symptoms [44].

Polygenic scores could be useful to investigate the associations between disease risk and severity of illness,symptoms and early treatment or later functional outcomes [45]. This method could potentially be used to stratify clinical high-risk (CHR) populations into groups with shared genetic features,

to identify those CHR individuals who would benefit from early therapeutic interventions. Future imaging genomics studies with larger samples may therefore not only lead to the discovery of biological pathways and links between genetic factors and alterations in brain networks [46], but also become a major predictive tool in the investigation of the early intervention of psychiatric disorder [47].

\section{Limitations}

Some limitations to our study must be kept in mind. Firstly, the sample size is moderately small. However, confounding biases in this difficult-to-collect cohort are relatively unlikely, due to the relatively homogenous genetic background and clinical characteristics, such as disease duration [48]. Additionally, small samples can make use of polygenic risk scores derived from large GWAS which generate robust estimators [49]. Secondly, replication studies are needed to evaluate this association further by meta-analytic procedures and gain insight into the presence or absence of an effect in the early stages of psychosis. Thirdly, the explained variance in liability to schizophrenia due to the PSRS is small. Therefore, only be speculated 
about genetic differences between ARMS-NT and ARMS-T+FEP. The actual differences need further investigation. Fourthly, future studies might analyze diffusion tensor imaging (DTI) data rather than 3D $\mathrm{T}_{1}$-weighted MPRAGE data. Then, in a SDM meta-analysis [50] it was estimated that fractional anisotropy analyses may be more sensitive to identifying changes in white matter than VBM analyses. Fifthly, we are aware that no conclusion can be drawn from this study regarding non-affective versus affective psychoses, as the aim was to include patients with a first psychotic episode, independent of the underlying diagnosis according to ICD/DSM classification systems. Sixthly, due to the focus on the potential association between white matter volume and the polygenic schizophrenia-related risk score (PSRS) this study does not include a healthy control group but patients before and after the onset of psychosis. Finally, although there is a significant difference in age between the groups, we showed in previous study of grey matter volume and cortical thickness a similar pattern of structural alterations in ARMS and FEP [51]. However, this will not exclude the possibility that ARMS-NT patients will develop to ARMS-T or even FEP patients during the time-course.

\section{Conclusion}

In summary, this is the first analysis to evaluate the impact of white matter volume and a PSRS on the onset of psychosis. Although we could not confirm an association, we report that greater values of PSRS are associated with ARMS-T and FEP status than with ARMS-NT. Moreover, the PSRS was associated with BPRS total score. These results might indicate that ARMS-T and FEP patients have a higher genetic risk for schizophrenia than ARMS-NT. This aspect should be investigated in further studies analyzing the prediction of psychosis from the at-risk mental state.

\section{Acknowledgments}

We thank all involved specialists as well as all patients for taking part in the study.

\section{Funding}

This project was supported by Grants of the UPK Forschungsförderungsfonds (No. 25038 to F.H.) and the Swiss National Science Foundation (No. 3232BO-119 382). These institutions had no further role in the study design; collection, analysis and interpretation of data; in the writing of the report and in the decision to submit the paper for publication.

\section{Disclosure Statement}

The authors declare no potential conflict of interest.

\section{References}

1 Sullivan PF, Daly MJ, O'Donovan M: Genetic architectures of psychiatric disorders: the emerging picture and its implications. Nat Rev Genet 2012;13:537-551.

2 McGuffin P, Rijsdijk F, Andrew M, Sham P, Katz R, Cardno A: The heritability of bipolar affective disorder and the genetic relationship to unipolar depression. Arch Gen Psychiatry 2003;60:497-502.

-3 Cross-Disorder Group of the Psychiatric Genomics C, Lee SH, Ripke S, Neale BM, Faraone SV, Purcell SM, Perlis RH, Mowry BJ, Thapar A, Goddard ME, Witte JS, Absher D, Agartz I, Akil H, Amin F, Andreassen OA, Anjorin A, Anney R, Anttila V, Arking DE, Asherson P, Azevedo MH, Backlund L, Badner JA, Bailey AJ, Banaschewski T, Barchas JD, Barnes MR, Barrett TB, Bass N, Battaglia A, Bauer M, Bayes M, Bellivier F, Bergen SE, Berrettini W, Betancur C, Bettecken T, Biederman J, Binder EB, Black DW, Blackwood DH, 


\section{Cellular Physiology Cell Physiol Biochem 2018;48:1201-1214 and Biochemistry Published onIIne: July 25, $2018 \quad \begin{aligned} & \text { DOI: 10.1159/000491986 } 2018 \text { The Author(s). Published by S. Karger AG, Basel } \\ & \text { www.karger.com/cpb }\end{aligned}$}

Harrisberger et al.: White Matter and Genetic Risk in Psychosis

Bloss CS, Boehnke M, Boomsma DI, Breen G, Breuer R, Bruggeman R, Cormican P, Buccola NG, Buitelaar JK, Bunney WE, Buxbaum JD, Byerley WF, Byrne EM, Caesar S, Cahn W, Cantor RM, Casas M, Chakravarti A, Chambert K, Choudhury K, Cichon S, Cloninger CR, Collier DA, Cook EH, Coon H, Cormand B, Corvin A, Coryell WH, Craig DW, Craig IW, Crosbie J, Cuccaro ML, Curtis D, Czamara D, Datta S, Dawson G, Day R, De Geus EJ, Degenhardt F, Djurovic S, Donohoe GJ, Doyle AE, Duan J, Dudbridge F, Duketis E, Ebstein RP, Edenberg HJ, Elia J, Ennis S, Etain B, Fanous A, Farmer AE, Ferrier IN, Flickinger M, Fombonne E, Foroud T, Frank J, Franke B, Fraser C, Freedman R, Freimer NB, Freitag CM, Friedl M, Frisen L, Gallagher L, Gejman PV, Georgieva L, Gershon ES, Geschwind DH, Giegling I, Gill M, Gordon SD, Gordon-Smith K, Green EK, Greenwood TA, Grice DE, Gross M, Grozeva D, Guan W, Gurling H, De Haan L, Haines JL, Hakonarson H, Hallmayer J, Hamilton SP, Hamshere ML, Hansen TF, Hartmann AM, Hautzinger M, Heath AC, Henders AK, Herms S, Hickie IB, Hipolito M, Hoefels S, Holmans PA, Holsboer F, Hoogendijk WJ, Hottenga JJ, Hultman CM, Hus V, Ingason A, Ising M, Jamain S, Jones EG, Jones I, Jones L, Tzeng JY, Kahler AK, Kahn RS, Kandaswamy R, Keller MC, Kennedy JL, Kenny E, Kent L, Kim Y, Kirov GK, Klauck SM, Klei L, Knowles JA, Kohli MA, Koller DL, Konte B, Korszun A, Krabbendam L, Krasucki R, Kuntsi J, Kwan P, Landen M, Langstrom N, Lathrop M, Lawrence J, Lawson WB, Leboyer M, Ledbetter DH, Lee PH, Lencz T, Lesch KP, Levinson DF, Lewis CM, Li J, Lichtenstein P, Lieberman JA, Lin DY, Linszen DH, Liu C, Lohoff FW, Loo SK, Lord C, Lowe JK, Lucae S, MacIntyre DJ, Madden PA, Maestrini E, Magnusson PK, Mahon PB, Maier W, Malhotra AK, Mane SM, Martin CL, Martin NG, Mattheisen M, Matthews K, Mattingsdal M, McCarroll SA, McGhee KA, McGough JJ, McGrath PJ, McGuffin P, McInnis MG, McIntosh A, McKinney R, McLean AW, McMahon FJ, McMahon WM, McQuillin A, Medeiros H, Medland SE, Meier S, Melle I, Meng F, Meyer J, Middeldorp CM, Middleton L, Milanova V, Miranda A, Monaco AP, Montgomery GW, Moran JL, Moreno-De-Luca D, Morken G, Morris DW, Morrow EM, Moskvina V, Muglia P, Muhleisen TW, Muir WJ, Muller-Myhsok B, Murtha M, Myers RM, Myin-Germeys I, Neale MC, Nelson SF, Nievergelt CM, Nikolov I, Nimgaonkar V, Nolen WA, Nothen MM, Nurnberger JI, Nwulia EA, Nyholt DR, O'Dushlaine C, Oades RD, Olincy A, Oliveira G, Olsen L, Ophoff RA, Osby U, Owen MJ, Palotie A, Parr JR, Paterson AD, Pato CN, Pato MT, Penninx BW, Pergadia ML, Pericak-Vance MA, Pickard BS, Pimm J, Piven J, Posthuma D, Potash JB, Poustka F, Propping P, Puri V, Quested DJ, Quinn EM, Ramos-Quiroga JA, Rasmussen HB, Raychaudhuri S, Rehnstrom K, Reif A, Ribases M, Rice JP, Rietschel M, Roeder K, Roeyers H, Rossin L, Rothenberger A, Rouleau G, Ruderfer D, Rujescu D, Sanders AR, Sanders SJ, Santangelo SL, Sergeant JA, Schachar R, Schalling M, Schatzberg AF, Scheftner WA, Schellenberg GD, Scherer SW, Schork NJ, Schulze TG, Schumacher J, Schwarz M, Scolnick E, Scott LJ, Shi J, Shilling PD, Shyn SI, Silverman JM, Slager SL, Smalley SL, Smit JH, Smith EN, Sonuga-Barke EJ, St Clair D, State M, Steffens M, Steinhausen HC, Strauss JS, Strohmaier J, Stroup TS, Sutcliffe JS, Szatmari P, Szelinger S, Thirumalai S, Thompson RC, Todorov AA, Tozzi F, Treutlein J, Uhr M, van den Oord EJ, Van Grootheest G, Van Os J, Vicente AM, Vieland VJ, Vincent JB, Visscher PM, Walsh CA, Wassink TH, Watson SJ, Weissman MM, Werge T, Wienker TF, Wijsman EM, Willemsen G, Williams N, Willsey AJ, Witt SH, Xu W, Young AH, Yu TW, Zammit S, Zandi PP, Zhang P, Zitman FG, Zollner S, Devlin B, Kelsoe JR, Sklar P, Daly MJ, O'Donovan MC, Craddock N, Sullivan PF, Smoller JW, Kendler KS, Wray NR, International Inflammatory Bowel Disease Genetics C: Genetic relationship between five psychiatric disorders estimated from genome-wide SNPs. Nat Genet 2013;45:984-994.

-4 Schizophrenia Working Group of the Psychiatric Genomics C: Biological insights from 108 schizophreniaassociated genetic loci. Nature 2014;511:421-427.

Lee SH, DeCandia TR, Ripke S, Yang J, Schizophrenia Psychiatric Genome-Wide Association Study C, International Schizophrenia C, Molecular Genetics of Schizophrenia C, Sullivan PF, Goddard ME, Keller MC, Visscher PM, Wray NR: Estimating the proportion of variation in susceptibility to schizophrenia captured by common SNPs. Nat Genet 2012;44:247-250.

-6 Ripke S, O'Dushlaine C, Chambert K, Moran JL, Kahler AK, Akterin S, Bergen SE, Collins AL, Crowley JJ, Fromer M, Kim Y, Lee SH, Magnusson PK, Sanchez N, Stahl EA, Williams S, Wray NR, Xia K, Bettella F, Borglum AD, Bulik-Sullivan BK, Cormican P, Craddock N, de Leeuw C, Durmishi N, Gill M, Golimbet V, Hamshere ML, Holmans P, Hougaard DM, Kendler KS, Lin K, Morris DW, Mors O, Mortensen PB, Neale BM, O'Neill FA, Owen MJ, Milovancevic MP, Posthuma D, Powell J, Richards AL, Riley BP, Ruderfer D, Rujescu D, Sigurdsson E, Silagadze T, Smit AB, Stefansson H, Steinberg S, Suvisaari J, Tosato S, Verhage M, Walters JT, Multicenter Genetic Studies of Schizophrenia C, Levinson DF, Gejman PV, Kendler KS, Laurent C, Mowry BJ, O'Donovan MC, Owen MJ, Pulver AE, Riley BP, Schwab SG, Wildenauer DB, Dudbridge F, Holmans P, Shi J, Albus M, Alexander M, Campion D, Cohen D, Dikeos D, Duan J, Eichhammer P, Godard S, Hansen M, Lerer FB, Liang KY, Maier W, Mallet J, Nertney DA, Nestadt G, Norton N, O'Neill FA, Papadimitriou GN, Ribble R, 


\section{Cellular Physiology Cell Physiol Biochem 2018;48:1201-1214

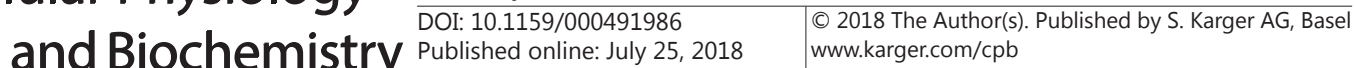

Harrisberger et al.: White Matter and Genetic Risk in Psychosis

Sanders AR, Silverman JM, Walsh D, Williams NM, Wormley B, Psychosis Endophenotypes International C, Arranz MJ, Bakker S, Bender S, Bramon E, Collier D, Crespo-Facorro B, Hall J, Iyegbe C, Jablensky A, Kahn RS, Kalaydjieva L, Lawrie S, Lewis CM, Lin K, Linszen DH, Mata I, McIntosh A, Murray RM, Ophoff RA, Powell J, Rujescu D, Van Os J, Walshe M, Weisbrod M, Wiersma D, Wellcome Trust Case Control C, Donnelly P, Barroso I, Blackwell JM, Bramon E, Brown MA, Casas JP, Corvin AP, Deloukas P, Duncanson A, Jankowski J, Markus HS, Mathew CG, Palmer CN, Plomin R, Rautanen A, Sawcer SJ, Trembath RC, Viswanathan AC, Wood NW, Spencer CC, Band G, Bellenguez C, Freeman C, Hellenthal G, Giannoulatou E, Pirinen M, Pearson RD, Strange A, Su Z, Vukcevic D, Donnelly P, Langford C, Hunt SE, Edkins S, Gwilliam R, Blackburn H, Bumpstead SJ, Dronov S, Gillman M, Gray E, Hammond N, Jayakumar A, McCann OT, Liddle J, Potter SC, Ravindrarajah R, Ricketts M, Tashakkori-Ghanbaria A, Waller MJ, Weston P, Widaa S, Whittaker P, Barroso I, Deloukas P, Mathew CG, Blackwell JM, Brown MA, Corvin AP, McCarthy MI, Spencer CC, Bramon E, Corvin AP, O'Donovan MC, Stefansson K, Scolnick E, Purcell S, McCarroll SA, Sklar P, Hultman CM, Sullivan PF: Genomewide association analysis identifies 13 new risk loci for schizophrenia. Nat Genet 2013;45:1150-1159.

7 International Schizophrenia C, Purcell SM, Wray NR, Stone JL, Visscher PM, O'Donovan MC, Sullivan PF, Sklar P: Common polygenic variation contributes to risk of schizophrenia and bipolar disorder. Nature 2009;460:748-752.

Flint J, Munafo MR: The endophenotype concept in psychiatric genetics. Psychol Med 2007;37:163-180. Gottesman, II, Shields J: Genetic theorizing and schizophrenia. Br J Psychiatry 1973;122:15-30. Preston GA, Weinberger DR: Intermediate phenotypes in schizophrenia: a selective review. Dialogues Clin Neurosci 2005;7:165-179.

-11 Haijma SV, Van Haren N, Cahn W, Koolschijn PC, Hulshoff Pol HE, Kahn RS: Brain volumes in schizophrenia: a meta-analysis in over 18000 subjects. Schizophr Bull 2013;39:1129-1138.

12 Shepherd AM, Laurens KR, Matheson SL, Carr VJ, Green MJ: Systematic meta-review and quality assessment of the structural brain alterations in schizophrenia. Neurosci Biobehav Rev 2012;36:1342-1356.

13 De Peri L, Crescini A, Deste G, Fusar-Poli P, Sacchetti E, Vita A: Brain structural abnormalities at the onset of schizophrenia and bipolar disorder: a meta-analysis of controlled magnetic resonance imaging studies. Curr Pharm Des 2012;18:486-494.

-14 van Haren NE, Rijsdijk F, Schnack HG, Picchioni MM, Toulopoulou T, Weisbrod M, Sauer H, van Erp TG, Cannon TD, Huttunen MO, Boomsma DI, Hulshoff Pol HE, Murray RM, Kahn RS: The genetic and environmental determinants of the association between brain abnormalities and schizophrenia: the schizophrenia twins and relatives consortium. Biol Psychiatry 2012;71:915-921.

-15 Terwisscha van Scheltinga AF, Bakker SC, van Haren NE, Derks EM, Buizer-Voskamp JE, Boos HB, Cahn W, Hulshoff Pol HE, Ripke S, Ophoff RA, Kahn RS, Psychiatric Genome-wide Association Study C: Genetic schizophrenia risk variants jointly modulate total brain and white matter volume. Biol Psychiatry 2013;73:525-531.

16 Papiol S, Mitjans M, Assogna F, Piras F, Hammer C, Caltagirone C, Arias B, Ehrenreich H, Spalletta G: Polygenic determinants of white matter volume derived from GWAS lack reproducibility in a replicate sample. Transl Psychiatry 2014;4:e362.

-17 Oertel-Knochel V, Lancaster TM, Knochel C, Stablein M, Storchak H, Reinke B, Jurcoane A, Kniep J, Prvulovic D, Mantripragada K, Tansey KE, O'Donovan MC, Owen MJ, Linden DE: Schizophrenia risk variants modulate white matter volume across the psychosis spectrum: evidence from two independent cohorts. Neuroimage Clin 2015;7:764-770.

18 Van der Auwera S, Wittfeld K, Homuth G, Teumer A, Hegenscheid K, Grabe HJ: No association between polygenic risk for schizophrenia and brain volume in the general population. Biol Psychiatry 2015;78:e4142.

19 Van der Auwera S, Wittfeld K, Shumskaya E, Bralten J, Zwiers MP, Onnink AM, Usberti N, Hertel J, Volzke H, Volker U, Hosten N, Franke B, Grabe HJ: Predicting brain structure in population-based samples with biologically informed genetic scores for schizophrenia. Am J Med Genet B Neuropsychiatr Genet 2017;174:324-332.

20 Fusar-Poli P: The Clinical High-Risk State for Psychosis (CHR-P), Version II. Schizophr Bull 2017;43:44-47.

-21 Fusar-Poli P, Bonoldi I, Yung AR, Borgwardt S, Kempton MJ, Valmaggia L, Barale F, Caverzasi E, McGuire P: Predicting psychosis: meta-analysis of transition outcomes in individuals at high clinical risk. Arch Gen Psychiatry 2012;69:220-229. 


\section{Cellular Physiology Cell Physiol Biochem 2018;48:1201-1214 \begin{tabular}{l|l} 
DOI: 10.1159/000491986 & $\begin{array}{l}\text { O } 2018 \text { The Author(s). Published by S. Karger AG, Basel } \\
\text { www.karger.com/cpb }\end{array}$ \\
\hline and Biochemistry
\end{tabular}}

22 Riecher-Rossler A, Gschwandtner U, Aston J, Borgwardt S, Drewe M, Fuhr P, Pfluger M, Radu W, Schindler C, Stieglitz RD: The Basel early-detection-of-psychosis (FEPSY)-study--design and preliminary results. Acta Psychiatr Scand 2007;115:114-125.

-23 Riecher-Rossler A, Pflueger MO, Aston J, Borgwardt SJ, Brewer WJ, Gschwandtner U, Stieglitz RD: Efficacy of using cognitive status in predicting psychosis: a 7-year follow-up. Biol Psychiatry 2009;66:1023-1030.

24 Riecher-Rossler A, Aston J, Ventura J, Merlo M, Borgwardt S, Gschwandtner U, Stieglitz RD: [The Basel Screening Instrument for Psychosis (BSIP): development, structure, reliability and validity]. Fortschr Neurol Psychiatr 2008;76:207-216.

-25 Yung AR, Phillips LJ, McGorry PD, McFarlane CA, Francey S, Harrigan S, Patton GC, Jackson HJ: Prediction of psychosis. A step towards indicated prevention of schizophrenia. Br J Psychiatry Suppl 1998;172:14-20.

-26 Harrisberger F, Smieskova R, Vogler C, Egli T, Schmidt A, Lenz C, Simon AE, Riecher-Rossler A, Papassotiropoulos A, Borgwardt S: Impact of polygenic schizophrenia-related risk and hippocampal volumes on the onset of psychosis. Transl Psychiatry 2016;6:e868.

27 Ho BC, Andreasen NC, Ziebell S, Pierson R, Magnotta V: Long-term antipsychotic treatment and brain volumes: a longitudinal study of first-episode schizophrenia. Arch Gen Psychiatry 2011;68:128-137.

28 Chang CC, Chow CC, Tellier LC, Vattikuti S, Purcell SM, Lee JJ: Second-generation PLINK: rising to the challenge of larger and richer datasets. Gigascience 2015;4:7.

29 Price AL, Patterson NJ, Plenge RM, Weinblatt ME, Shadick NA, Reich D: Principal components analysis corrects for stratification in genome-wide association studies. Nat Genet 2006;38:904-909.

30 Delaneau 0, Zagury JF, Marchini J: Improved whole-chromosome phasing for disease and population genetic studies. Nature Methods 2013;10:5-6.

-31 Howie BN, Donnelly P, Marchini J: A flexible and accurate genotype imputation method for the next generation of genome-wide association studies. PLoS Genet 2009;5:e1000529.

-32 Howie B, Marchini J, Stephens M: Genotype imputation with thousands of genomes. G3 (Bethesda) 2011;1:457-470.

-33 Purcell S, Neale B, Todd-Brown K, Thomas L, Ferreira MA, Bender D, Maller J, Sklar P, de Bakker PI, Daly MJ, Sham PC: PLINK: a tool set for whole-genome association and population-based linkage analyses. Am J Hum Genet 2007;81:559-575.

34 Wray NR, Lee SH, Mehta D, Vinkhuyzen AA, Dudbridge F, Middeldorp CM: Research review: Polygenic methods and their application to psychiatric traits. J Child Psychol Psychiatry 2014;55:1068-1087.

-35 Fischl B: FreeSurfer. Neuroimage 2012;62:774-781.

- 36 Najjar S, Pearlman DM: Neuroinflammation and white matter pathology in schizophrenia: systematic review. Schizophr Res 2015;161:102-112.

37 Shafer A, Dazzi F, Ventura J: Factor structure of the Brief Psychiatric Rating Scale - Expanded (BPRS-E) in a large hospitalized sample. J Psychiatr Res 2017;93:79-86.

- 38 Honea R, Crow TJ, Passingham D, Mackay CE: Regional deficits in brain volume in schizophrenia: a metaanalysis of voxel-based morphometry studies. Am J Psychiatry 2005;162:2233-2245.

-39 Vita A, De Peri L, Sacchetti E: Gray matter, white matter, brain, and intracranial volumes in first-episode bipolar disorder: a meta-analysis of magnetic resonance imaging studies. Bipolar Disord 2009;11:807-814.

-40 Schmidt A, Lenz C, Smieskova R, Harrisberger F, Walter A, Riecher-Rossler A, Simon A, Lang UE, McGuire P, Fusar-Poli P, Borgwardt SJ: Brain Diffusion Changes in Emerging Psychosis and the Impact of StateDependent Psychopathology. Neurosignals 2015;23:71-83.

41 Harris JM, Moorhead TW, Miller P, McIntosh AM, Bonnici HM, Owens DG, Johnstone EC, Lawrie SM: Increased prefrontal gyrification in a large high-risk cohort characterizes those who develop schizophrenia and reflects abnormal prefrontal development. Biol Psychiatry 2007;62:722-729.

-42 Fusar-Poli P, Cappucciati M, Borgwardt S, Woods SW, Addington J, Nelson B, Nieman DH, Stahl DR, Rutigliano G, Riecher-Rossler A, Simon AE, Mizuno M, Lee TY, Kwon JS, Lam MM, Perez J, Keri S, Amminger P, Metzler S, Kawohl W, Rossler W, Lee J, Labad J, Ziermans T, An SK, Liu CC, Woodberry KA, Braham A, Corcoran C, McGorry P, Yung AR, McGuire PK: Heterogeneity of Psychosis Risk Within Individuals at Clinical High Risk: A Meta-analytical Stratification. JAMA Psychiatry 2016;73:113-120.

-43 Fusar-Poli P, Tantardini M, De Simone S, Ramella-Cravaro V, Oliver D, Kingdon J, Kotlicka-Antczak M, Valmaggia L, Lee J, Millan MJ, Galderisi S, Balottin U, Ricca V, McGuire P: Deconstructing vulnerability for psychosis: Meta-analysis of environmental risk factors for psychosis in subjects at ultra high-risk. Eur Psychiatry 2017;40:65-75. 


\section{Cellular Physiology Cell Physiol Biochem 2018;48:1201-1214 \begin{tabular}{l|l} 
DOI: 10.1159/000491986 & O 2018 The Author(s). Published by S. Karger AG, Basel \\
www.karger.com/cpb
\end{tabular} \\ Harrisberger et al.: White Matter and Genetic Risk in Psychosis}

44 Plomin R, Haworth CM, Davis OS: Common disorders are quantitative traits. Nat Rev Genet 2009;10:872878.

45 Ranlund S, Calafato S, Thygesen JH, Lin K, Cahn W, Crespo-Facorro B, de Zwarte SMC, Diez A, Di Forti M, Group, Iyegbe C, Jablensky A, Jones R, Hall MH, Kahn R, Kalaydjieva L, Kravariti E, McDonald C, McIntosh AM, McQuillin A, Peic, Picchioni M, Prata DP, Rujescu D, Schulze K, Shaikh M, Toulopoulou T, van Haren N, van Os J, Vassos E, Walshe M, Wtccc, Lewis C, Murray RM, Powell J, Bramon E: A polygenic risk score analysis of psychosis endophenotypes across brain functional, structural, and cognitive domains. Am J Med Genet B Neuropsychiatr Genet 2018;177:21-34.

-46 Dezhina Z, Ranlund S, Kyriakopoulos M, Williams SCR, Dima D: A systematic review of associations between functional MRI activity and polygenic risk for schizophrenia and bipolar disorder. Brain Imaging Behav 2018;10.1007/s11682-018-9879-z

47 Schmidt A, Borgwardt S: Editorial: Third-Generation Neuroimaging: Translating Research into Clinical Utility. Front Psychiatry 2016;7:170.

-48 Fusar-Poli P, Cappucciati M, Bonoldi I, Hui LM, Rutigliano G, Stahl DR, Borgwardt S, Politi P, Mishara AL, Lawrie SM, Carpenter WT, Jr., McGuire PK: Prognosis of Brief Psychotic Episodes: A Meta-analysis. JAMA Psychiatry 2016;73:211-220.

49 Dudbridge F: Power and predictive accuracy of polygenic risk scores. PLoS Genet 2013;9:e1003348.

50 Bora E, Fornito A, Radua J, Walterfang M, Seal M, Wood SJ, Yucel M, Velakoulis D, Pantelis C: Neuroanatomical abnormalities in schizophrenia: a multimodal voxelwise meta-analysis and metaregression analysis. Schizophr Res 2011;127:46-57.

-51 Dukart J, Smieskova R, Harrisberger F, Lenz C, Schmidt A, Walter A, Huber C, Riecher-Rossler A, Simon A, Lang UE, Fusar-Poli P, Borgwardt S: Age-related brain structural alterations as an intermediate phenotype of psychosis. J Psychiatry Neurosci 2017;42:307-319. 